\title{
Comparative study of purifications technologies and their application to HVAC systems
}

\author{
Davide Truffo ${ }^{1 *}$, Josè Miguel Peña Suarèz ${ }^{2}$, Juan Bandera Cantalejo ${ }^{2}$, Marìa Del Carmen \\ Gonzalez Muriano ${ }^{2}$, Francisco Garcias Vacas ${ }^{3}$, Francisco Fernandez Hernàndez ${ }^{4}$. \\ ${ }^{1}$ Airzone Italia - Cormano, Italy \\ ${ }^{2}$ Corporación Empresarial Altra S.L. - Málaga, Spain \\ ${ }^{3}$ Mechanical Engineering Group of the University of Malaga - Málaga, Spain \\ ${ }^{4}$ Energy Group of the University of Malaga - Málaga, Spain
}

\begin{abstract}
Nowadays, there is a growing demand to guarantee indoor air quality in buildings. This study presents a solution that combines hygrothermal control and purification of the air supplied to occupied spaces, in which the control and purification system is integrated into the air distribution ductwork. Among all the air purification technologies, not all of them are suitable to be used in the residential and tertiary sector along with already installed HVAC systems. In this study, a review of the state of the art of technologies is made and the major purification techniques are analysed and compared, i.e., negative ionization, ozone, ultraviolet light, photocatalytic oxidation, and high-efficiency filtration. The comparison is focused on key aspects such as the use with occupation, whether there is a biocide or not, whether it can be used with HVAC units, costs, and maintenance. Finally, an effective and viable purification solution for HVAC systems is presented. It consists of a compact device based on the ionization technology. An ionizer device is placed in the air in-take of ducted HVAC units that is capable of remotely controlling the main operating parameters of the HVAC equipment (switching on and off, operating mode, fan speed, and setpoint temperature) while reducing the suspension time of fine particles in the air. Various studies carried out in Airzone laboratories have empirically shown that the use of this device results in a $47 \%$ reduction in the maximum concentration of particulate matter of $2.5 \mu \mathrm{m}$ or PM2.5 and up to a $55 \%$ reduction of the time these particles are suspended in the air.
\end{abstract}

\section{INTRODUCTION}

The developed solutions that combine hygrothermal control and purification of the air supplied to occupied spaces are very interesting for control companies. It is important to consider the following as initial premises in the development:

- The purification treatment can be carried out in the presence of people.

- The control and purification system is integrated into the air distribution network, taking advantage of the characteristics of the HVAC system fans.

Thanks to the negative ionization technology in conjunction with zoning control solutions, it is possible to remotely control the main operating parameters (on/off, operating mode, fan

\footnotetext{
*Corresponding author: davide@truffo.it
} 
speed and set temperature) of the ducted units and reduce the suspension time of fine particles in the air. The physical principle of ionization is applied in this return plenum, enhanced by the mechanical capture of particles in the device itself.

This paper collects information from various commercial solutions for air purification and the advantages of negative ionization above the rest.

\section{INDOOR AIR QUALITY AND PM2.5 PARTICLES}

Indoor air quality, among other aspects, is closely linked to the absence of suspended particles.

Particulate matter is a heterogeneous and complex mixture of liquid and/or solid particles, of organic and inorganic substances, which are suspended in the air. Particulate matter is part of air pollution and represents a risk to human health, so they are even considered (Directive 2008/50/EC) an air pollutant, along with $\mathrm{SO}_{2}$ (sulfur dioxide), $\mathrm{NO}_{\mathrm{x}}$ (nitrogen oxides), $\mathrm{CO}$ (carbon monoxide), $\mathrm{Pb}$ (lead), $\mathrm{C}_{6} \mathrm{H}_{6}$ (benzene) and $\mathrm{O}_{3}$ (ozone). The composition of the particulate material is very varied, being its main components, sulphates, nitrates, ammonia, sodium chloride, coal, mineral dust, metallic ashes, pollen, dust mites, tobacco smoke, etc.

Particulate material is catalogued according to its size:

- Coarse particles: $10 \mu \mathrm{m}>$ equivalent aerodynamic diameter $>2.5 \mu \mathrm{m}$;

- Fine particles: equivalent aerodynamic diameter $<2.5 \mu \mathrm{m}$.

Chronic prolonged exposure to particulate matter increases the risk of cardiovascular disease (Liang, F. et al. 2020), respiratory disease (asthma (Hakan, L. et al. 2020), lung disorders (Hou, D. et al. 2020) or allergies (Wang, M. et al. 2020)) and lung cancer (RaaschouNielsen, O. et al. 2016). Due to their size, $\mathrm{PM}_{2.5}$ particles pose a greater health risk than $\mathrm{PM}_{10}$ particles, for three reasons.

1) They can travel deep into the lungs, penetrating the respiratory system and depositing themselves in the pulmonary alveoli, even reaching the bloodstream. So, they could damage any organ in the human body.

2) They are composed of more toxic elements (such as heavy metals and organic compounds) than those present in larger particles.

3) They are lighter and remain longer in suspension in the air. This not only prolongs their negative effects, but also facilitates their transport in the air.

For these reasons, the World Health Organization (WHO 2005) sets the exposure threshold for $\mathrm{PM}_{2.5}$ particles at $10 \mu \mathrm{g} / \mathrm{m}^{3}$ (annual average) and $25 \mu \mathrm{g} / \mathrm{m}^{3}$ (24-hour average). For $\mathrm{PM}_{10}$ particles, the exposure threshold is $20 \mu \mathrm{g} / \mathrm{m}^{3}$ (annual average) and $50 \mu \mathrm{g} / \mathrm{m}^{3}$ (24-hour average).

\section{PURIFICATION TECHNOLOGIES}

There are different commercial solutions on the market to treat the air in occupied spaces.

\subsection{Ozone}

Ozone $\left(\mathrm{O}_{3}\right)$ is a substance whose molecule consists of three oxygen atoms formed by the dissociation of two oxygen atoms, typically in gas phase.

Ozone generation is achieved by passing a flow of oxygen through two electrodes. Thereby, applying a certain voltage, a current of electrons is caused in the space delimited by the electrodes. These electrons will cause the dissociation of oxygen molecules that will later form ozone. 
Ozone is a powerful oxidant that reacts with proteins and lipids, particularly with biological membranes. Its use as a disinfectant agent requires high concentrations. An $\mathrm{O}_{3}$ concentration greater than $2 \mathrm{mg} / \mathrm{m}^{3}$ already begins to have disinfection effects and its maximum effectiveness as a virucidal is reached with concentrations between 39 and $49 \mathrm{mg} / \mathrm{m}^{3}$ (Schwartz, A. et al. 2020).

According to the World Health Organization air quality recommendations (WHO 2005), the limit for ozone concentration is $100 \mu \mathrm{g} / \mathrm{m}^{3}$ for an average of 8 hours.

Another factor to bear in mind in the use of ozone as a purification technology is that it is not included in the list of virucidal products authorized by the Spanish Ministry of Health (Productos virucidas autororizados en España. 2020).

In addition, according to the standard UNE 400201:1994, it is convenient to place the ozone generator at a height of not less than $220 \mathrm{~cm}$ and its installation must be carried out by a specialist technician.

\subsection{Ultraviolet radiation}

It is an electromagnetic radiation whose wavelength is between approximately $100 \mathrm{~nm}(100$ $\left.\times 10^{-9} \mathrm{~m}\right)$ and $400 \mathrm{~nm}\left(400 \times 10^{-9} \mathrm{~m}\right)$. Likewise, the UV spectrum is subdivided into the following segments:

- UV-A (long wave between 400 and $315 \mathrm{~nm}$ );

- UV-B (medium wave between 315 and $280 \mathrm{~nm}$ );

- UV-C (short wave between 200 and $280 \mathrm{~nm}$ );

- UV (vacuum between 200 and $100 \mathrm{~nm}$ ).

Ultraviolet light can be generated artificially by using an emitter (called a lamp) made of pure quartz, placed inside a chamber that contains an inert gas (mercury vapor). By inducing an electric current in the poles of the lamp, an electric arc is caused, and the gas is ionized. Additionally, the heat produced by the emitter increases together with the internal pressure of the gas, which increases the excitation of electrons causing them to move through the different wavelength lines, to the point of converting them into photons of UV light.

Ultraviolet light has germicidal properties. Microorganisms are inactivated by UV light as a result of nucleic acid damage. Cellular DNA and RNA absorb the high energy associated with electromagnetic radiation (Buonanno, M. et al. 2020). An exposure to $24.1 \mathrm{~mJ} / \mathrm{cm}^{2}$ has an efficiency of $90 \%$. To reach $99 \%$ the exposure must reach $50 \mathrm{~mJ} / \mathrm{cm}^{2}$ (Kowalski, W. et al. 2020).

UVGI (Ultraviolet Germicidal Irradiation) germicidal technology does not use chemicals for disinfection. However, its use in public settings is limited because UV exposure can be harmful to health. Prolonged exposure of the skin should be avoided and especially avert continuous contact with eyes without protection, as otherwise it could lead to carcinogenic and cataract effects.

Directive 2006/25/EC establishes the maximum exposure for people and indicates that the limit values (at $254 \mathrm{~nm}$ ) are $2.8 \mathrm{~mJ} / \mathrm{cm}^{2}$ of daily dose (in 8 hours) and that in no case should they be overcome.

Another aspect to consider with this technology is the photo-oxidative degradation of polymers when they receive direct radiation (Ghatge, N. et al 1971).

\subsection{Photocatalytic oxidation}

It is a process in which surfaces coated with titanium dioxide $\left(\mathrm{TiO}_{2}\right)$ become chemically reactive to organic compounds when exposed to ultraviolet light. By irradiating a $\mathrm{TiO}_{2}$ lay- 
er, electrons are released for a short period of time during which they can participate in localized chemical reactions that can produce hydroxyl radicals and other ions.

Hydroxyl radicals are highly reactive, and they will oxidize volatile organic compounds, in addition to many chemical pollutants. There is evidence that this treatment can inactivate both viruses and bacteria, (Takehara, K., et al. 2010).

The restrictions of use are very similar to those presented in the previous section on the use of ultraviolet light.

\subsection{High efficiency filtration}

An air filter is a device made of fibrous or porous materials that reduces the concentration of solid particles such as dust, pollen, mold, and bacteria in the air.

High-efficiency filters are made of braided fibers responsible for screening microscopic particles. To retain these very small particles, the high-efficiency filters generate a high resistance to airflow. When they are completely clean, they can generate around $200 \mathrm{~Pa}$ of pressure drop, which makes it impossible to use them with conventional fans of ducted units. These filters should not be installed near humidification and dehumidification systems and the incoming air should never be saturated.

The following are among the high-efficiency filters:

- EPA (Efficiency Particulate Air);

- HEPA (High Efficiency Particulate Air);

- ULPA (Ultra Low Penetration Air).

Classification by particle filtration is regulated under the EN ISO 16890:2016 standard.

\subsection{Negative ionization}

Air ionization is a process that occurs when electrons are removed from or added to atoms, causing an imbalance in the charge. The electrical configurations of the ions formed in the air thus include $\mathrm{H}+, \mathrm{H}_{3} \mathrm{O}+, \mathrm{O}+, \mathrm{N}+, \mathrm{OH}-, \mathrm{H}_{2} \mathrm{O}$ - and $\mathrm{O}-$.

Such ionized molecules act as condensation nuclei that grow and increase their mass when small particles are agglutinated. In this way, they precipitate more easily and are captured by thicker filters.

The ionization of the air allows to reduce the suspension time of the particles reducing the inhaled particles up to 46\% (Tanaka A. et al. 1996), (Mayya, Y. S. et al. 2004) and (Sawant, V. S. 2013). With this technique it is possible to achieve rates of particle removal $20 \%$ higher than those achieved by high efficiency filtration (Pushpawela, B. et al. 2017) and (Lee, B. U. et al. 2004).

There is also scientific evidence on the benefits of ionization to prevent the effect of allergies due to dust mites, pet hair, tobacco smoke, or pollen (according to the studies of Cutis, N. J. et al 2003, Goodman, N. et al. 2004, Sawant, V. S. et al. 2012 and Kawamoto, S. et al. 2006).

The ionized molecules in the air also affect the volatile organic compounds (according to the studies of Wu, C. C. et al 2004 and Kim, K. et al. 2017), eliminate bacteria (Serratia marcescens (Phillips, G. et al. 1964 and Zhoua, P. et al. 2018), E. coli (Tyagi, A. K. et al. 2008 and Noyce, J. O. et al. 2002, Candida albicans (Shargawi, J. M. et al. 1999), Staphylococcus aureus (Dobrynin, D. et al 2011) or P. fluorescens (Timoshkin, I. V. et al. 2012) and inhibit viruses (NDV (Bailey, W. et al. 1994) and Influenza (Hagbom, M. et al. 2015)). Ionized molecules deteriorate the outer membrane of viruses and expose their RNA to oxidation.

The dissemination of ions is achieved by electrostatic repulsion. The migration of ions will depend on the alignment of the magnetic field generated between the point of emission and 
the surrounding objects. The concentration of the ions surrounding the generators is not homogeneous and decreases significantly with distance. Therefore, their installation with fans will increase the ion dispersion zone.

The process of ionization of the air can be carried out artificially through different mechanisms. In recent years, air ionization techniques have made exponential progress, evolving from ionization lamps to state-of-the-art needle technology. This has made it possible to drastically reduce the size of the equipment and minimize maintenance and replacement costs.

The current world situation has popularized the implementation of different air purification technologies. However, not all of them are suitable for use in the residential and commercial sectors coupled with existing air conditioning equipment.

\subsection{Technology comparison}

The above technologies will then be compared based on suitability for use in conventional HVAC equipment.

Firstly, it should be noted that HVAC units operate most of the time in the presence of people. Therefore, it is critical that the treatment is safe for humans and pets that may occupy the conditioned space. For this reason, ozonation technology should not be embedded in HVAC units, because high concentrations are needed $(2 \mathrm{mg} / \mathrm{m} 3)$ for its biocidal effect to be considerable. In the case of ultraviolet radiation and photocatalytic oxidation, it would be necessary to avoid direct exposure of light to the occupants. In split-type equipment located in the occupied area, there is not enough space inside to create that protective screen that allows air circulation.

Secondly, the air conditioning units are made up of pieces of different materials (see Figure 1). On the one hand, ozone has high oxidizing power and the metal parts (chassis, heat exchanger, PCBs, electronic components, fan motor, etc.) will have premature corrosion. On the other hand, UV radiation treatment has a high degree of photo-oxidative degradation in polymers, and the plastic parts (fan volute, thermal insulation, etc.) will rapidly deteriorate. There are surface treatments to avoid these effects, but conventional air conditioning units are not marketed with these finishes.

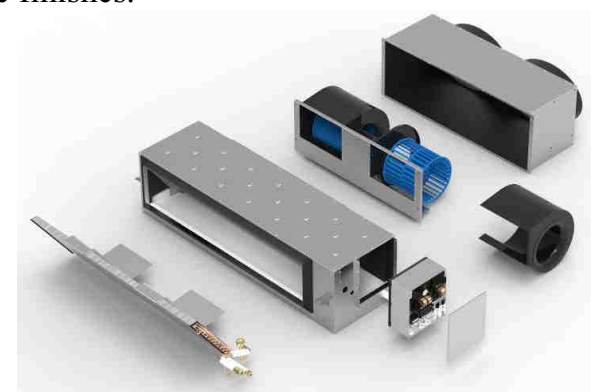

Figure 1. Different parts in a duct indoor unit.

Finally, conventional units have a maximum external static pressure between 50 and $80 \mathrm{~Pa}$. High efficiency filters increase their pressure drop exponentially as they become clogged. Therefore, they are not compatible with conventional units. An alternative is to install a separate air distribution network with a higher static pressure fan. This solution also has disadvantages, in addition to the extra cost, it is necessary to consider the balancing of the air distribution network, the possible increase in noise and the need for additional space necessary for the new ducts and the fan. 
To better understand each technology, Table I summarizes the characteristics of the main technologies on the market explained in previous sections. 


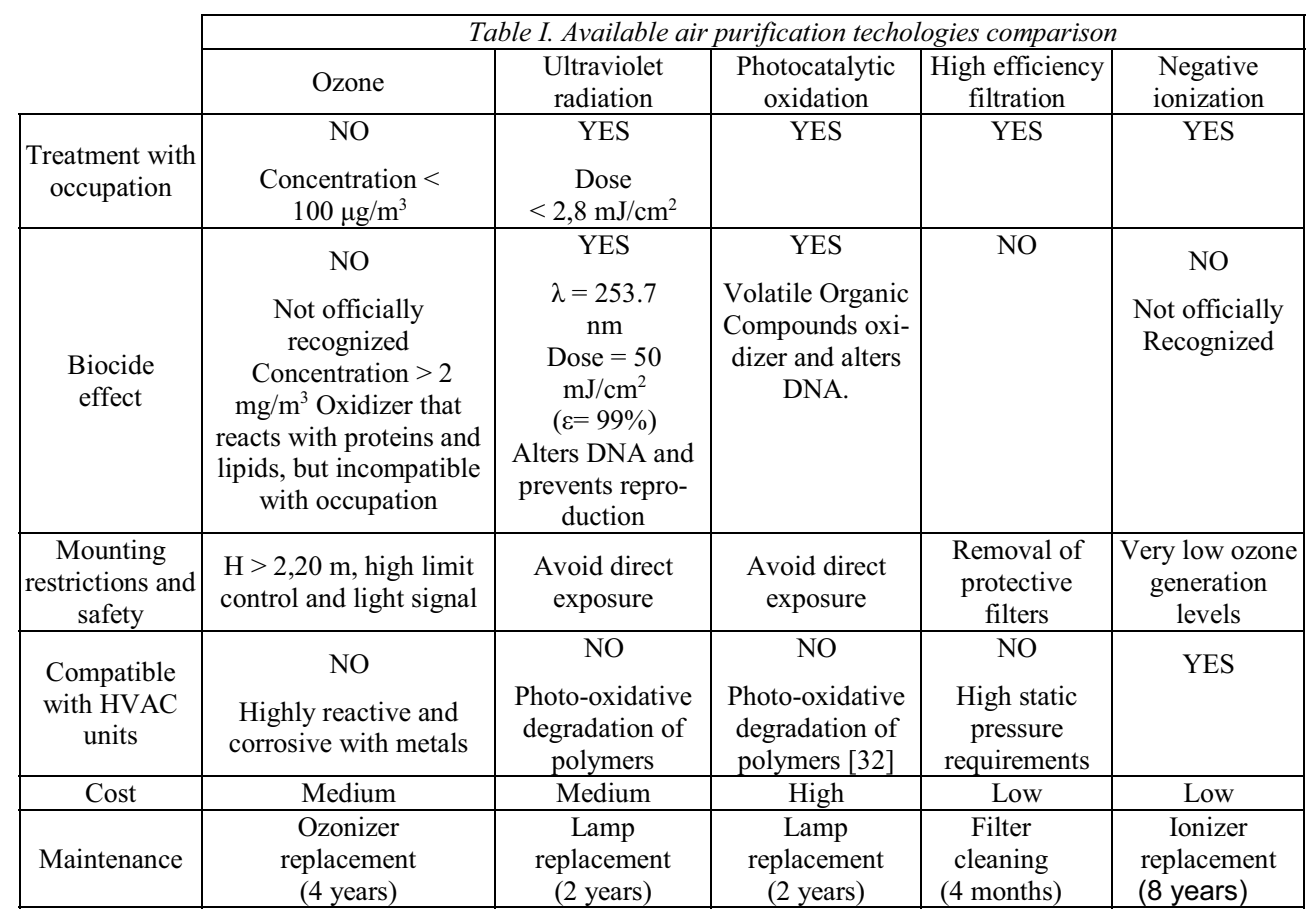

This comparison shows that the ionization technology is the only one compatible with conventional air conditioning equipment used in the residential and commercial sectors.

In addition, it is a treatment that allows people to be present in the room.

\section{LABORATORY TEST}

The technology developed by Airzone has undergone various performance tests. The tests carried out are described below and the results obtained in these tests are shown.

\subsection{Removal of PM2.5 particles}

The laboratory has a room that emulates the real conditions of a home or office.

The test room has a volume of $70 \mathrm{~m}^{3}$, with stoneware floor and plaster ceiling and walls. The dimensions of this room are: length $7.15 \mathrm{~m}$, width $3.80 \mathrm{~m}$ and height $2.55 \mathrm{~m}$.

A ducted unit (model: ADEA35A2VEB) has been used in the test. The air distribution network consists of the following elements:

- Easyzone air supply motorized plenum AZEZ6DAIST07S3;

- 10 meters of insulated circular flexible duct with 3 elbows;

- Grille plenum;

- Diffusion grille $300 \times 150 \mathrm{~mm}$;

- Return plenum AZIAQDAPR07S;

The concentration of $\mathrm{PM}_{2.5}$ is artificially generated through the combustion of 4 incense sticks.

In the first test the purification system of the AZIAQDAPR07S device is deactivated. In the second test the purification system is activated. In both cases the temporal evolution of the concentration of $\mathrm{PM}_{2.5}$ is monitored by a network of sensors (Honeywell HMP and Pana- 
sonic SN-GCJA5) placed both in the room and in the supply and return air distribution network.

The ducted unit has always been tested by selecting low fan speed. Therefore, the air flow rate to the room is $360 \mathrm{~m}^{3} / \mathrm{h}$ (which means 5 renewals/hour) with the air velocity on the grill of approximately $2.5 \mathrm{~m} / \mathrm{s}$.

Figure 2 shows the temporal evolution of the concentration measured in the return plume. The four rods are consumed in an interval of approximately one hour. During this period, the particle concentration rises. The maximum peak with the purification system deactivated (orange line) is $512 \mu \mathrm{g} / \mathrm{m}^{3}$, while with the purification system activated (green line) it only reaches the value of $273 \mu \mathrm{g} / \mathrm{m}^{3}$. This means a $47 \%$ reduction in the maximum concentration point during the test.

Once the sticks are consumed, the concentration of particles begins to decrease. However, when the purification system is deactivated (orange line) a total time of 11 hours and 45 minutes is required to remove all particles. While with the purification system active (green line) only 5 hours and 20 minutes are required to reach the same point. This means that the airborne time for $\mathrm{PM}_{2.5}$ has been reduced by $55 \%$ when using the ionizer device.

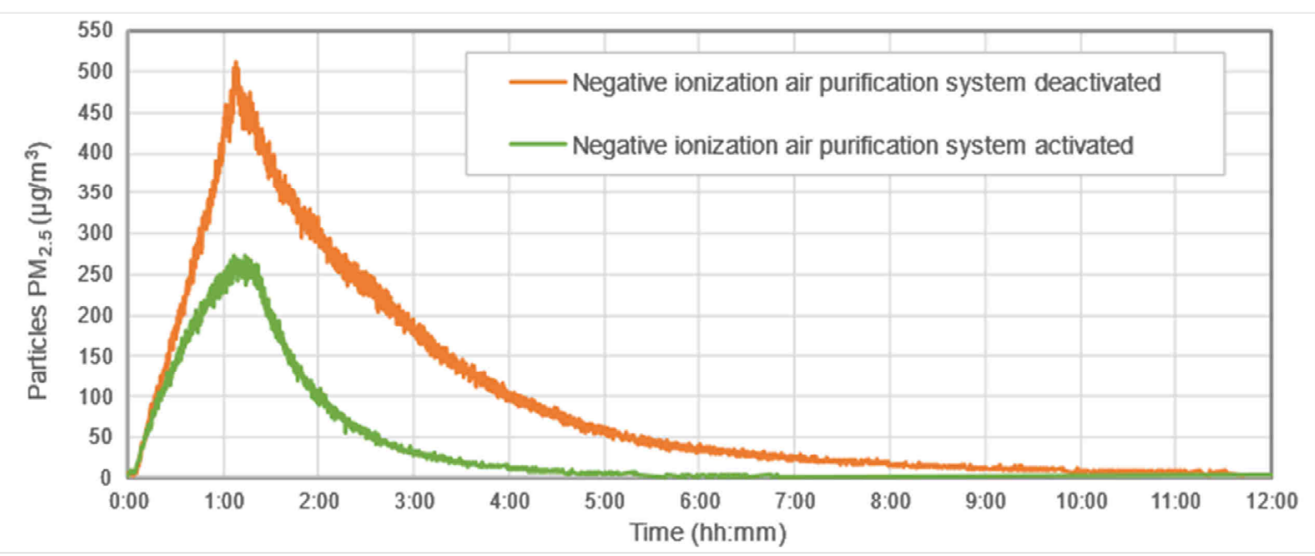

Figure 2. Temporal evolution of PM2.5 particles concentration.

The beneficial effect of the negative ionization solution on indoor air quality due to the absence of suspended particles is therefore clear.

\subsection{Antiviral effect}

The BSA (Biomedical Sciences Association) of the University of Texas Veterinary Medicine and Biomedical Sciences has demonstrated the inhibitory effect of the technology used by the purification solution on the Influenza H3N2 virus, reducing its infectivity rate.

The infectivity rate is defined as the number of viral particles capable of invading a host cell.

During the test, the Influenza H3N2 virus was spread by a nebulizer in a chamber box. This test box has a volume of 120 liters. The environmental conditions during the test are constant and equal to a temperature of $25^{\circ} \mathrm{C}$ and a relative humidity of $40 \%$ (similar to the environmental conditions of a home or office). 


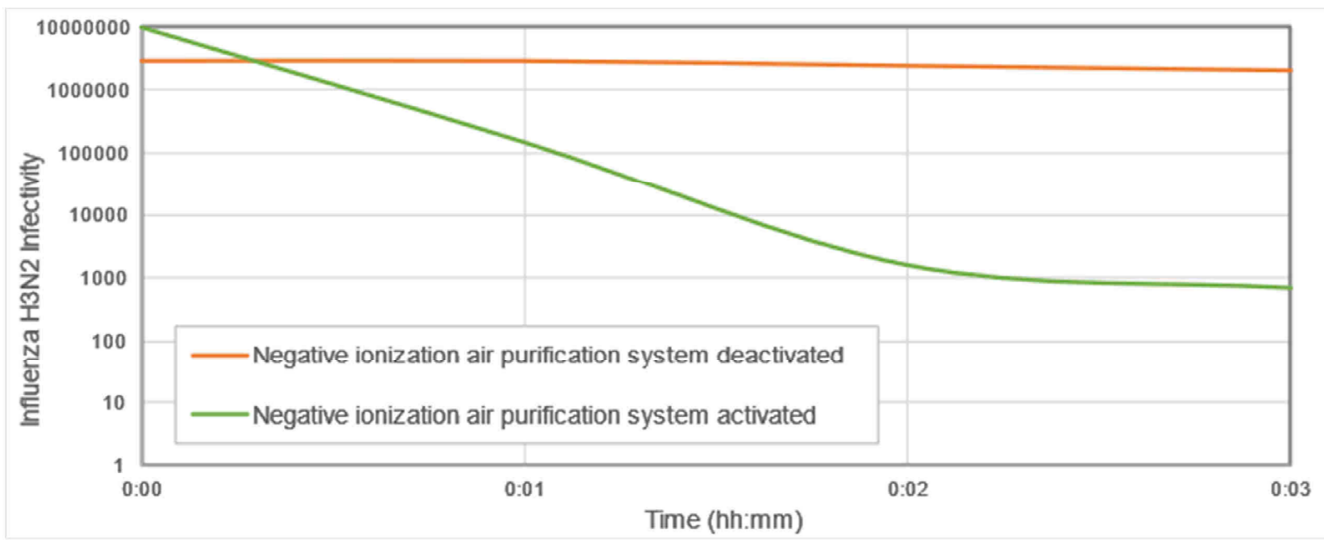

Figure 3. Temporal evolution of the infectivity rate of the Influenza H3N2 virus. Source: Murata Manufacturing Co., Ltd - Biomedical Sciences Association (Texas A\&M University).

Figure 3 shows the temporal evolution of the infectivity rate of the Influenza H3N2 virus. In it, it is observed how the infectivity rate barely decreases when the ionizer purification system is kept deactivated (orange line). However, in the first two minutes there is a logarithmic drop when the Negative ionization system is activated (green line). After three minutes of exposure, infectivity has decreased from $10^{7}$ to 700 . Therefore, direct exposure of negative ionization technology is shown to have an inhibitory effect on viruses.

\subsection{Antibacterial effect}

The Japanese laboratory Boken Quality Evaluation Institute has demonstrated the high antibacterial potential of the technology used in the negative ionization solution, specifically against Bacillus coli and Staphylococcus aureus.

During the tests, the bacteria are inoculated on a plastic surface inside a 9-liter container. Standard testing is 24 hours with ambient conditions kept constant at a temperature of $35^{\circ} \mathrm{C}$ and a relative humidity of $90 \%$ (according to JIS Z2801 standard). The Japanese Industrial Standard (JIS) Z2801 is a quantitative antimicrobial test that is commonly requested for plastics, foams, and textiles and is harmonized with ISO 22196.

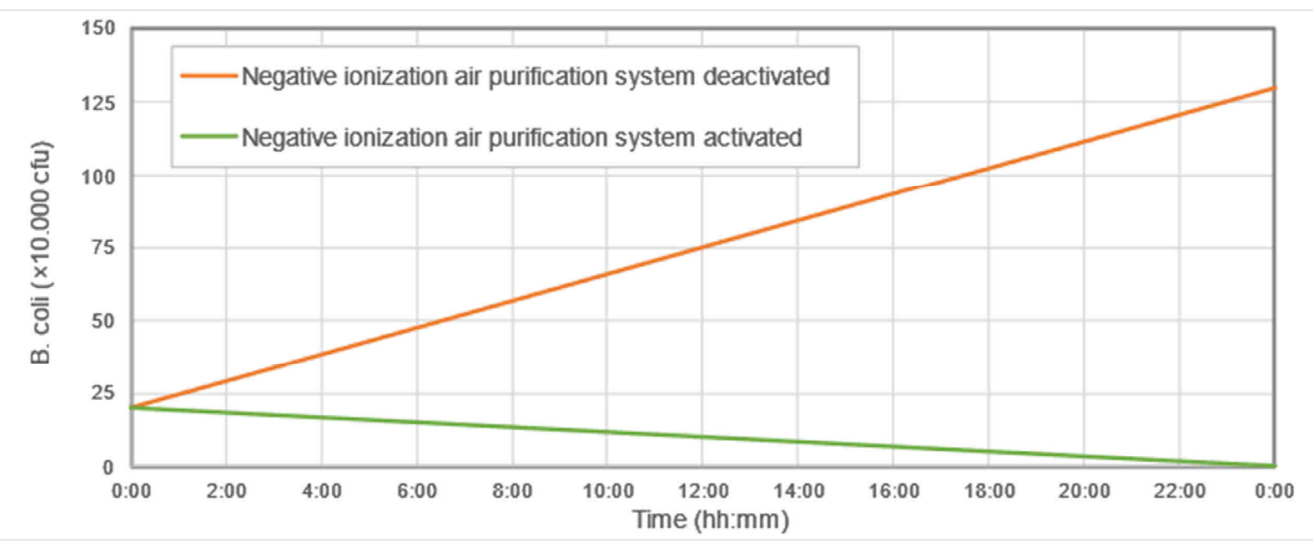

Figure 4. Temporal evolution of the count in colony-forming units of Bacillus coli. Source: Murata Manufacturing Co., Ltd - Boken Quality Evaluation Institute. 


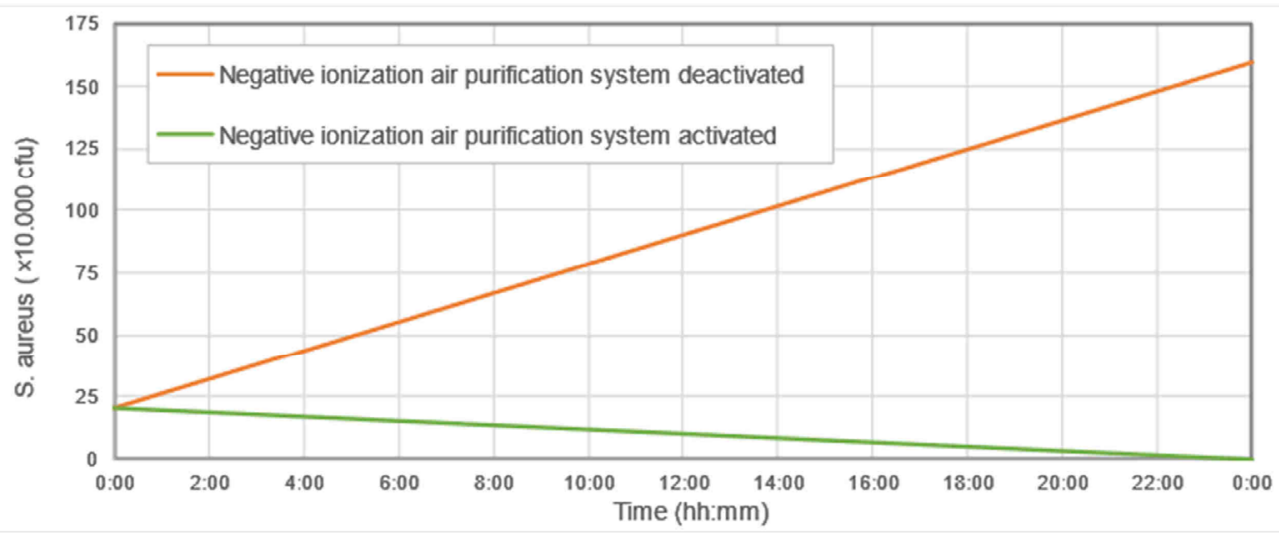

Figure 5. Temporal evolution of the count in colony-forming units of Staphylococcus aureus. Source: Murata Manufacturing Co., Ltd - Boken Quality Evaluation Institute.

Figure 4 shows the evolution over time of Bacillus coli colony-forming units. It shows how, in one day, the colony thrives up to $130 \mathrm{cfu}$ with the Negative ionization system deactivated (orange line). While the colony is eliminated in one day when the Negative ionization system is activated (green line).

Figure 5 shows the temporal evolution in colony-forming units of Staphylococcus aureus. It shows how in one day the colony thrives up to $160 \mathrm{cfu}$ with the Negative ionization system deactivated (orange line). While the colony is eliminated in one day when the Negative ionization system is activated (green line).

\subsection{Deodorizing effect over VOCs}

The Japanese laboratory Boken Quality Evaluation Institute has demonstrated the powerful deodorizing effect of negative ionization solution for sources of volatile organic compounds, specifically $\mathrm{CH}_{2} \mathrm{O}$ (formaldehyde) and $\mathrm{H}_{2} \mathrm{~S}$ (hydrogen sulfide).

The tests are carried out in a $30 \mathrm{~m}^{3}$ test chamber and the results shown are in percentage because they are based on olfactory units (OU), where:

$O U=$ Concentration of the compound / Odor threshold of the compound.

In the case of formaldehyde $\left(\mathrm{CH}_{2} \mathrm{O}\right)$ the threshold is $490 \mu \mathrm{g} / \mathrm{m}^{3}$. For hydrogen sulfide $\left(\mathrm{H}_{2} \mathrm{~S}\right)$ the threshold is $30 \mu \mathrm{g} / \mathrm{m}^{3}$. These values are the initial concentrations of the tests and therefore, the graphs start at $100 \%$.

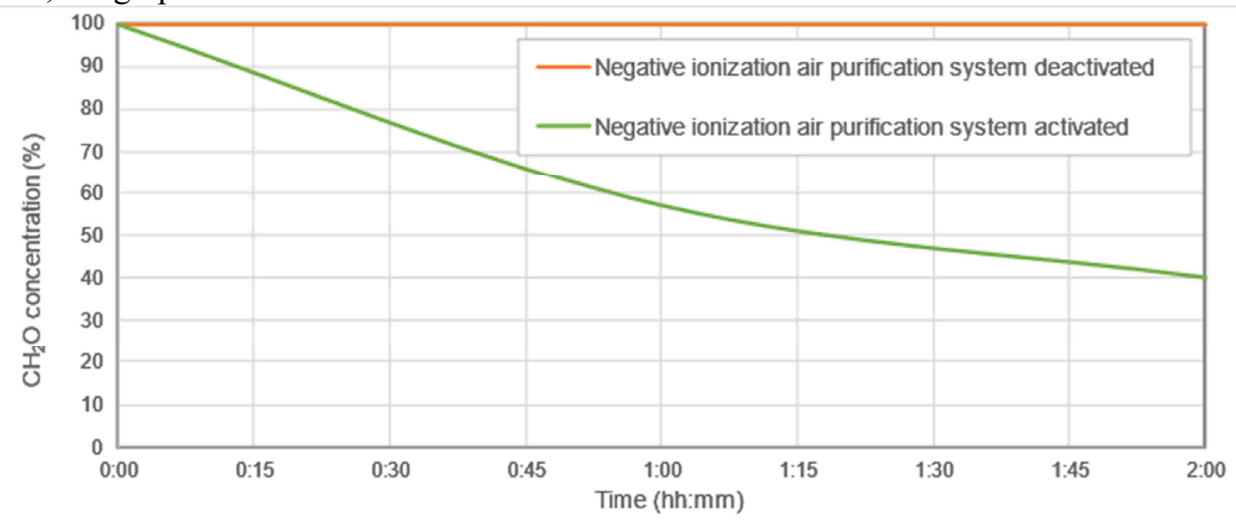

Figure 6. Temporal evolution of $\mathrm{CH}_{2} \mathrm{O}$ (formaldehyde) concentration Source: Murata Manufacturing Co., Ltd - Boken Quality Evaluation Institute. 


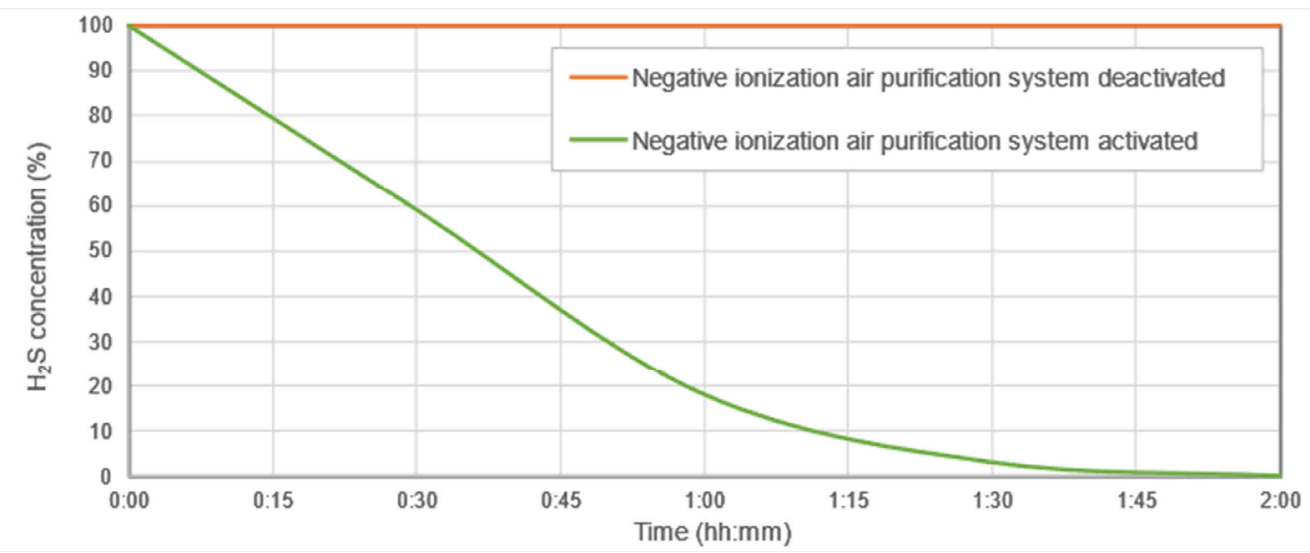

Figure 7. Temporal evolution of $\mathrm{H}_{2} \mathrm{~S}$ (hydrogen sulphide) concentration. Source: $\mathrm{Mu}-$ rata Manufacturing Co., Ltd - Boken Quality Evaluation Institute.

Figure 6 shows the temporal evolution of $\mathrm{CH}_{2} \mathrm{O}$ concentration. It shows a reduction of $60 \%$ in the volatile organic compound of formaldehyde with an exposure time of 2 hours.

Figure 7 shows the temporal evolution of $\mathrm{H}_{2} \mathrm{~S}$ concentration. It shows a $100 \%$ reduction in the volatile organic compound of hydrogen sulfide with an exposure time of 2 hours.

These tests show that negative ionization technology reduces volatile organic compounds and mitigates unpleasant environmental odors.

\section{CONCLUSIONS}

The performance information on the negative ionization solution allows us to state that it is a safe and compact device, capable of improving indoor air quality in the following aspects:

- Reduction of fine particles in suspension in the air, with higher performance than high efficiency filtration;

- Benefits against respiratory problems and allergies caused by dust mites, pet hair, tobacco smoke and pollen;

- Elimination of odors by reducing VOCs in the air;

- Inhibition of bacteria and viruses;

All this, without impairing the functional performance of indoor unit fans.

The conjunction between a zoned control system and negative ionization not only improves indoor air quality, but also reduces electricity consumption by decreasing the rate of outdoor air supplied to conditioned spaces and allows remote control of units with ducts.

All these features make this solution an enhancer for green building certifications such as BREEAM or LEED, where a higher score could be achieved.

\section{BIBLIOGRAPHY}

1. Klepeis, N. et al. 2001. Human Activity Pattern Survey (NHAPS): a resource for assessing exposure to environmental pollutants. Journal of Exposure Analysis and Environmental Epidemiology. Vol. 11, pp 231-252.

2. Directive 2008/50/EC of the European Parliament and of the Council of 21 May 2008 on ambient air quality and cleaner air for Europe. 
3. Liang, F. et al. 2020. Long-Term Exposure to Fine Particulate Matter and Cardiovascular Disease in China. Journal of the American College of Cardiology. Vol. 75-7, pp 707-717.

4. Hakan, L. et al. 2008. Particulate Matter (PM2.5, PM10-2.5 and PM10) and Children's Hospital admission for Asthma and Respiratory Diseases: A Bidirectional CaseCrossover Study. Journal of Toxicology and Environmental Health. Vol. 71-8.

5. Hou, D. et al. 2020. Associations of long-term exposure to ambient fine particulate matter and nitrogen dioxide with lung function: A cross-sectional study in China. Environmental International. Vol. 144.

6. Wang, M. et al. 2020. The association between PM2.5 exposure and daily outpatient visits for allergic rhinitis: evidence from a seriously air-polluted environment. International Journal of Biometeorology. Vol. 64, pp 139-144.

7. Raaschou-Nielsen, O. et al. 2016. Particulate matter air pollution components and risk for lung cancer. Environmental International. Vol. 87, pp 66-73.

8. WHO. 2005. Occupational and Environmental Health Team. WHO Air quality guidelines for particulate matter, ozone, nitrogen dioxide and sulfur dioxide. Global update 2005 Summary of risk assessment.

9. Schwartz, A. and Martínez-Sánchez, G. 2020. Potential use of ozone in SARS-CoV-2 / COVID-19. International Scientific Committee of Ozone Therapy. ISCO3.ISCO3/EPI/00/04.

10. Productos virucidas autorizados en España. 2020. Secretaría de Estado de Sanidad. Subdirección General de Sanidad Ambiental y Salud Laboral.

11. UNE 400201:1994. Generadores de ozono. Tratamiento de aire. Seguridad química.

12. Buonanno, M., Welch, D., Shuryak, I. and Brenner D. J. Far-UVC light (222 nm) efficiently and safely inactivates airborne human coronaviruses. 2020. Scientific reports. Vol 10: 10285 | https://doi.org/10.1038/s41598-020-67211.

13. Kowalski, W., Walsh, T. and Petraitis, V. 2020 COVID-19 Coronavirus Ultraviolet Susceptibility. 2020. Researchgate Technical Report. DOI: 10.13140/RG.2.2.22803.22566.

14. Ghatge, N. and Vernekar, S. 1971. Evaluation of ultraviolet light absorbers in poly vinyl chloride (PVC). Macromolecular Materials and Engineering. Vol. 20-1, pp 175180.

15. Directive 2006/25/EC. Minimum health and safety requirements regarding the exposure of workers to risks arising from physical agents (artificial optical radiation).

16. Takehara, K., Yamazaki, K., Miyazaki, M., Yamada, Y., Ruenphet, S., Jahangir, A, Shoham, D., Okamura, M., Nakamura, M. 2010. Inactivation of avian influenza virus H1N1 by photocatalyst under visible light irradiation. Virus Res., Vol. 151, pp 102103.

17. EN ISO 16890: 2016. Air filters for general ventilation - Part 1: Technical specifications, requirements and classification system based upon particulate matter efficiency (ePM). 
18. Tanaka A. and Zhang, Y. 1996. Dust settling efficiency and electrostatic effect of a negative ionization system. Journal of Agricultural Safety and Health. Vol. 2-1, pp 3947.

19. Mayya, Y. S., Sapra, B. K., Khan, A. and Sunny, F. 2004. Aerosol removal by unipolar ionization in indoor environments. Journal of Aerosol Science. Vol.35-8, pp 923-941.

20. Sawant, V.S. 2013. Removal of particulate matter by using negative electric discharge. International Journal of Engineering and Innovative Technology. Vol. 2, pp 48-51.

21. Pushpawela, B., Jayaratne, R., Nguy, A and Morawska, L. 2017. Efficiency of ionizers in removing airbone particles in indoor environments. Journal of Electronics. Vol. 90, pp 79-84.

22. Lee, B. U., Yermakov, M. and Grinshpun, S. A. 2004. Removal of fine and ultrafine particles indoor air environment by the unipolar ion emission. Atmospheric Environment. Vol 38, pp 4815-4823.

23. Cutis, N. J., Woodfolk, J. A., Vaughan, J. W. and Platts-Mills, T. A. E. 2003. Quantitative measurement of airbone allergens from dust mites, dogs, and cats using an ioncharging device. Clinical \& Experimental Allergy. Vol. 33, pp 986-991.

24. Goodman, N. and Hughes, J. F. 2004. The effect of corona discharge on dust mite and cat allergens. Journal of Electrostatics. Vol. 60, pp 69-91.

25. Sawant, V. S., Meena, G. S. and Jadhav, D. B. 2012. Effect of negative air ions on fog and smoke. Aerosol and Air Quality Research. Vol 12, pp 1007-1015.

26. Kawamoto, S., Oshita, M., Fukuoka, N., Shigeta, S., Aki, T., Hayashi, T., Nishikawa, K. and Ono, K. 2006. Decrease in the Allergenicity of Japanese Cedar Pollen Allergen by Treatment with Positive and Negative Cluster Ions. International archives of allergy and immunology. Vol.141-4, pp 313-321.

27. Wu, C. C. and Lee, G. W. M. 2004. Oxidation of Volatile Organic Compounds by Negative Air Ions. Atmospheric Environment. Vol.38, pp 6287-6295.

28. Kim, K., Szulejko, J. E., Kumar, P., Kwon, E.E. and Adelodun, A. A. 2017. Air ionization as a control technology for off-gas emissions of volatile. Environmental Pollution. Vol. 225, pp 729-243.

29. Phillips, G., Harris, G. J. and Jones, M. W. 1964. Effects of air ions on bacterial aerosols. International Journal of Biometeorology. Vol.8, pp 27-37.

30. Zhoua, P., Yangc, Y., Huang, G. and Laib, C. K. 2018. Numerical and experimental study on airborne disinfection by negative ions in air duct flow. Building and Environmental. Vol. 127, pp 204-210.

31. Tyagi, A. K., Nirala, B. K., Malik, A. and Singh, K. 2008. The effect of negative air ion exposure on Escherichia coli and Pseudomonas fluorescens. Journal of Environmental Science and Health. Toxic/Hazardous Substances and Environmental Engineering. Vol. 43, pp 694-699.

32. Noyce, J. O. and Hughes, J. F. 2002. Bactericidal effects of negative and positive ions generated in nitrogen on Escherichia coli. Journal of Electrostatics. Vol. 54, pp 179187. 
33. Shargawi, J. M., Theaker, E. D., Drucker, D. B., MacFarlane, T. and Duxbury A. J. 1999. Sensitivity of Candida albicans to negative air ion streams. Journal Applied Microbiology. Vol. 87, pp 889-897.

34. Dobrynin, D., Friedman, G., Fridman, A. and Starikovskiy, A. 2011. Inactivation of bacteria using DC corona discharge: Role of ions and humidity. New Journal of Physics. Vol. 13.

35. Timoshkin, I. V., Maclean, M., Wilson, M. P., Given, M. J., MacGregor, S. J., Wang, T. and Anderson, J. G. 2012. Bactericidal effect of corona discharges in atmospheric air. IEEE Transactions on Plasma Science. Vol. 40-10, pp 2322-2333.

36. Bailey, W. Mitchell, P. and Daniel, J. K. 1994. Effect of Negative Air Ionization on Airborne Transmission of Newcastle Disease Virus. Avian Diseases. Vol. 38, pp 725732.

37. Hagbom, M., Nordgren, J., Nybom, R., Hedlund, K., Wigzell, H. and Svensson, L. 2015. Ionizing air effects influenza virus infectivity and prevents airborne transmission. Scientific Reports. Vol.5. 